\title{
Accessibility Improvement of Multicultural Educational Web Interface by using the User Centred Design (UCD) Approach
}

\author{
MD Shah Jahan Miah \\ Griffith University, Nathan Campus, Brisbane, Australia
}

Smiah123bd@yahoo.com

\begin{abstract}
Designing of web accessibility features need to accommodate cultural differences in the multicultural world. This paper finds the literature on how the web accessibility features of educational website can be improved for multicultural users by using the User Centred Design (UCD) approach. This paper reviews previous research on multicultural approach, accessibility functions and UCD approach. The reviews found some multicultural factors interpreted in terms of some cultural variables like Power distance, Uncertainty avoidance, Individualism, Universalism, Masculinity, Neutral Culture, Specific culture and Achievement level during the designing of multicultural web sites, and the close observation on multicultural user's understanding is important in designing well-functioned accessibility features.

This paper explores the background on the UCD approach in designing the multicultural web accessibility, beyond the access for users from different cultures. In particular, this paper intends to explain the opportunity of UCD approach in designing the multicultural accessibility features.
\end{abstract}

Keywords: User Centred Design, Participatory Design, Interfaces, Human interactions

\section{Introduction}

Gathering information from websites is becoming common practice in this era. No one knows for sure exactly how many people are online. One guess is, there are 605.60 million people online as of September 2002 (Nua Internet Surveys, 2002). Websites are like a big world market place for knowledge, products, and other services. Well accessible Websites can give us many benefits such as increased publicity, extended business area, enhanced service to users/customers, and improved user/customer satisfactions for organizations.

According to the report of IDP Education Australia (2003), it was found that the number of International students in Australian Universities is increasing rapidly every year. IDP Education Australia has conducted a survey on international students in 39 Australian Universities in semester one, 2003. The total number of enrolled international students in Australian Universities is estimated at 174,641 (IDP Education Australia, 2003). The increased rate is $15.5 \%$ from the semester

Material published as part of these proceedings, either on-line or in print, is copyrighted by Informing Science. Permission to make digital or paper copy of part or all of these works for personal or classroom use is granted without fee provided that the copies are not made or distributed for profit or commercial advantage AND that copies 1) bear this notice in full and 2) give the full citation on the first page. It is permissible to abstract these works so long as credit is given. To copy in all other cases or to republish or to post on a server or to redistribute to lists requires specific permission from the publisher at Publisher@InformingScience.org two, 2002. This IDP report represents growth of strong economical significance to the Australian economy.

For an educational institute, the web site is an important media to focus their offers such as information about degrees, fees, courses as well as the location easily to the world market. 
Using the website is going to become an essential communication media for Educational Institutes. The international students access the website of their preferred Universities to get the required information about the courses, fees, location and the other facilities like accommodation.

Design of website needs to satisfy the user's expectation. The information on the website should be easily accessible. The web accessibility features should be easily understood to the visitors from all over the world. Marcus (2000) describes that a well-designed web interface improves the performance and appeal of the web by helping to convert the target users like tourists to residents and browsers to customers. Evers (2001) defines that people from different cultures, have different cultural patterns in behaviour, communication, interaction and understanding. Thus, it is important to understand user's culture in order to improve the performance and appeal of the website.

The interface of web site provides accessibility features to users to access, find, see and use the information from websites. Marcus (2000) also defines in his paper that "Well-designed web accessibility provides the browser satisfactions, preferences and expectations by directing/transforming the information". It means that the interface needs to display the information easily to the users.

The paper addresses the literature on accessibility improvements for multicultural users in particular for the educational websites. The literature review aims to provide a basis for a Masters Research Project addressed the research question: How the accessibility of educational web can be improved by taking the UCD approach for multicultural users?

\section{Definition of Web Accessibility and User Centred Design}

It is important to clarify the concept about the UCD first. Beekhuyzen, von Hellens, Morley, and Nielsen (2003) describe the UCD as a participatory design approach when designing some thing closely related with users. As suggested in this paper, the UCD is one of the participatory design (PD) approach, focuses the users active involvement in design process and continuous observations during the designing. UCD ensures the users participation in the designing phase. Users have the opportunity to put their idea into product design directly according to their needs. The web accessibility needs to be defined in the paper at the beginning also. In Zaphiris and Zacharia (2001) papers, Letoumeau defines web accessibility to mean "anyone using any kind of web browsing technology must be able to visit any site and get a full and complete understanding of the information as well as have the full and complete ability to interact with the site if that is necessary". From this statement, it is easily defined that the accessibility of web means easy to access the information from it by simple and easiest way. The information presentation, information layout, set of icons, text format and buttons settings can become the factors to design the good accessibility features.

\section{Context of Paper}

This section discusses the papers goal, purpose as well as the research questions in details. The 'issues in the paper' section defines the goal aimed in this paper. The research question section describes the purpose and divides the sub questions from the research question.

\section{Issues in the Paper}

The goal aimed in this paper is to review and analyse the previous studies on the web accessibility features for the multicultural users. There are three related areas which are significant for the research question in the paper. The areas are Culture, Accessibility of Website and UCD approach. 


\section{Research Question}

The purpose of the research is to originate a design method for improving the multicultural web accessibility features. This paper reviews the previous studies on multicultural approach and the web accessibility improvements. The preliminary research question is in this paper as follows.

How can accessibility of educational website be improved for different cultural groups by taking a UCD approach?

Sub questions:

- How can UCD approach help to design a multicultural website for the educational institute?

- What are the accessibility features to be improved for multicultural users?Main

\section{Analysis and perceptions}

\section{Culture and Cultural Variables}

The previous multicultural research approach in Information System mostly supports the well famous Hofstede's cross-cultural theory. The five cultural dimensions of Hofstede are supported by a list of previous studies. The Studies (Evers, 2000; Evers \& Day, 1997; Marcus, 2000, 2001) suggested that multicultural factors interpret in terms of some cultural dimensions like Power distance, Uncertainty avoidance, Individualism, Universalism, Masculinity, Neutral Culture, Specific culture and Achievement level.

In order to assess the cultural differences between user's responses, Evers (2000) has included some cultural dimensions as follows:

- Power distance is the extent to which inequality is seen as an irreducible fact of life. In the culture with low power distance subordinates accept that superiors have more power than they have but are only right when they know the best way to do something. In high power distance culture, superiors and subordinates consider each as other unequal.

- Uncertainty avoidance measures the extent to which people in a culture feel threatened by and try to avoid ambiguous situations.

- Individualism is the concern for the individual as opposed to the concern for the priorities and rules of the group to which the individual belongs. Individual decisions whereas collectivist cultures feel more comfortable in anonymously attributing to the group decision.

- Masculinity concerns the extent of focus on work goals and assertiveness as opposed to personal goals and nurturing.

- Universalism focuses more on rules whereas particularism focuses more on relationships than rules.

- Neutral cultures would feel less comfortable in expressing emotions openly whereas for affective cultures, expressing emotions openly is more natural.

- Specific cultures tend to not mix private and professional life.

- Achievement oriented cultures focus more on how well they perform and how this performance is acknowledged by others. Status is based on what someone does in relation to the specific task or function.

Evers and Day (1997) defined the culture as a complex concept that interprets in forms of various dimensions. Evers and Day (1997) examined users culturally specific design preferences by doing 
survey on the 206 international students plus a control group of 38 Australian Students. Evers and Day (1997) found the results from the survey that indicate the design preferences do affect interface acceptance. The concept of literature also suggested that different cultures have their own cultural rules to show themselves.

According to the papers of Marcus (2001) and Evers (2000), the source of cultural issues arise from user needs, wants, expectations and preferences that is interpreted by the way of users behaviour, communication, interaction and understanding. Marcus (2000) introduced the wellrespected work of theorist Hofstede, and applied some of his cultural dimensions to web user interface design. Study of Marcus (2000) explained about Hofstedes survey on 53 countries IBM employees. As his description in this paper, Hofstede identified five dimensions of culture and rated 53 countries on indices for each dimension, normalized to values of 1 to 100 . The five dimensions are Power Distance, Collectivism vs. Individualism, Femininity vs. Masculinity, Uncertainty Avoidance, and Long vs. Short-term orientation. This report conducted an analytical observation on web interface design differences in between 53 countries ranked by Hofstede. Study investigated design issues on web interface raised by cultural dimensions. The issues are in the users interactions, motivations, style of argumentations, role and behaviour from the user point of view; the issues from the designer point of view are type of design objectives, target users, target cultures, cultural focuses and men-women differences in the different culture.

Marcus (2000) has included some real examples for present web design differences in different cultures. The interesting part of Marcus (2000) is the findings of the design differences through some sample websites design view. This paper identified the clear aspects of influence in web designing for specific cultural dimensions are as follows:

Power Distance (PD)

- Access to information: highly (high PD) vs. less-highly (Low PD) structured.

- Hierarchies in mental models: tell vs. shallow

- Emphasis on the social and moral order (nationalism or religion) and its symbols: significant/frequent vs. minor/infrequent use.

- Focus on expertise, authority, experts, certifications, official stamps, or logos: strong vs. week.

Individualism vs. collectivism

- Motivation based on personal achievement: maximized (expect the extra-ordinary) for individualist cultures vs. underplayed

- Images of success: demonstrated through materialism and consumerism vs. achievement of social political agendas.

- Rhetorical style: controversial/argumentative speech and tolerance or encouragement of extreme claims vs. official slogans and subdued hyperbole and controversy.

- Prominence given youth and action vs. aged, experienced.

- Importance given individuals vs. products shown by themselves or with group.

- Willingness to provide personal information.

Masculinity vs. Femininity

- Traditional gender/ family/age distinctions

- Work tasks, roles and mastery with quick results for limited tasks. 
- Navigation oriented to exploration and control

- Attention gained through games and competitions

- Graphics, sound and animation used for utilitarian purposes

Uncertainty Avoidance (UA)

- Simplicity, with clear metaphors, limited choices, and restricted amounts of data.

- Attempts to reveal the results or implications of actions before users act.

- Navigation (control vs. less control) schemes intended to prevent users from becoming lost.

- Mental models and help systems the focus on reducing users error Vs. focus on understanding underlying concept

- Redundant cues (colour, typography, sound) to reduce ambiguity.

Long vs. short term time orientation

- Content focused on practice and practical value vs. truth and certainty of beliefs

- Relationships vs. rules as a source of information and credibility

- Patience Vs. desire in achieving results and goals

This report also argued that the cross-cultural theory should be an accepted element in designing of user interface of website.

The term cultural dimension used in the Marcus (2000) is refined as cultural variable in Evers (2000) paper. Evers (2000) also included two more variables that were neutral culture and specific culture. Evers (2000) described the cultural variables as the indicator of culture in the society but the Marcus (2000) has followed Hofstede's definitions in this paper. Evers (2000) investigated the cultural differences in understanding elements of a virtual campus website in her survey report. 14 Dutch, 16 Japanese, 15 North American, and 14 British secondary students were involved in the research.

Evers (2000) found that culture classified some value orientation frequently used in the most of classical anthropological studies. The value orientations are the same as the cultural variables. This author concluded with a model of elements that indicates the influence of user understanding elements on interface. The gap of this study is, the paper did not investigate how the user understanding elements influenced by different cultures. The different cultures should have different set of understanding elements about the designing view. The understanding elements of users from different culture should be focused with the design view. According to (Evers, 2001), It is clear that the cultural variables makes the affects on the design view according to the culture where the users from. It is important to include the users understanding element, which can be variant with different cultures.

From the exploration of design difference through the sample website from different part of world in the paper of Marcus (2001) and from the point of view of Evers (2001), it is fair to conceptualise that users from different culture expect different design view as they think, act and communicate.

\section{Accessibility}

According to the source (Henry, 2003), accessibility is more concerned with making web sites perceivable, operable, and understandable. In the usability point of view, the web interface should 
be more effective, efficient and satisfying. Henry (2003) also described the important elements of accessibility features such as Learnability, Memorability, Effectiveness, Efficiency and Satisfaction in his conceptual discussion paper. According to the definition of accessibility in his conceptual paper, it is seems that the functions which is important to make the website more perfect to use easily with satisfaction that can be referred as accessibility features. The user's roles, right and activities are more important in designing the accessibility function in the definition. The effective and efficient web interaction becomes more important when the website is using for multicultural users.

Sierkowski (2002) defined the web accessibility is the ability for a person using any user agent (software or hardware that retrieves and renders web content) to understand and fully interact with a website's content. The idea of accessibility is based on more that the implementation of standards; it embodies the idea that everyone has the right to be included in society.

\section{User Centred Design}

UCD ensures that the users help to develop the products to suite their needs. Jokela (2000) defined the UCD as an approach to interactive system development that focuses specially on making systems usable. Jokela (2000) reviewed the usability capability models and analysed the designing of usability in this paper.

Beekhuyzen et al. (2003) suggested that the UCD focuses on the active involvement of the user in the design process, trying to obtain a clear understanding of exact task requirements, involving an iterative design and evaluation process and utilising a multi disciplinary approach. In their survey of the literature, Beekhuyzen et al. (2003) intended to search participatory design methodology for Smart Internet Technology Development. This research also suggested that the users are more important in the designing roles. The users can have a total participation with designer in the design phase. The designer can be given attention on understanding users from different culture. From the literature suggestion on UCD, it is clear that, the UCD design view encourages proper reflection of user's satisfactions during the designing.

Vredenburg, Isensee, and Righi (2002) defined that the UCD design principles are to involve the users by taking some steps during the development:

- Set business goals that determine the target market, intended users and primary competition.

- Understand users. An understanding of the user is the driving force behind all design.

- Design the total user experience. Everything a customer sees hears and touches is designed together by a multidisciplinary team.

- Assess competitiveness. Competitive design requires a relentless focus on the ways users currently carry out the tasks and a determination to make designs add value.

- Evaluate designs. User feedback is gathered often with rigor and speed and drives product design.

- Manage for users. User feedback is integral to product plans, priorities and decisions making.

Firstly, this statement states about the set of business goals. Determining the target market, the target users and primary competition can identify the business goals. The source of definition is the textbook " User Centred Design: An Integrated Approach" by Vredenburg et al. (2002); it is fair to say that the business goals of educational institute can be the internationalisation goals, 
because of the web accessibility function of the educational website is for the multicultural users around the world.

\section{Multicultural Website and UCD}

The online teaching and learning is based on the website of educational institute these days. As Simons (2000) stated in his paper, the online teaching and learning can be made user friendly only by paying the attention to cultural, organizational and personal learning values and patterns. This paper was a keynote speech presented at the International Simulation and Gaming Association (ISAGA) Conference and described the multicultural aspects on online training games.

The educational institute mainly universities web site is a great resource of information that is accessed by users from many cultures. Evers (2002) has emphasised on the interface localisation of virtual campus website. This paper discussed the findings of study from the investigation on multicultural international students. As the statement in the Simons (2000) paper, it is an obvious that the accessibility of the educational website have to reflect the total users experience and satisfactions by accommodating the cultural difference. The accessibility function should display the information according to the multicultural users learning patterns and their values.

According to the source (Evers, 2000), "a website is designed with a specific user group in mind, The users real world around them is potentially very difficult from the real world of the designers who made the website. Therefore, users from different cultural background will have difficulty understanding the virtual world on the screen that is modelled to a real world dissimilar of their own real word." Here the literature of this study suggested that the users from different culture have their own understanding. The understanding of user influences their behaviour with system how they interact with. As Beekhuyzen et al. (2003) described that the UCD offers the users participations during the designing. From this review, it is clear to say that the users can have active involvement to reflect their understanding into the design phase progressively for improving the accessibility features they want.

Evers (2000) defined that the users understanding elements (users understanding of text, users understanding of graphics elements, users understanding of metaphors, users understanding of general context, users understanding of cultural context) influences on the interface. It is not unfair to say from the statement of Evers (2000) that the users understanding elements are one of main factor in improving the accessibility features of the website. The accessibility features can become friendly and international by analysing the users understanding element. And by the way, education web site can reach to the goals of their business. The UCD approach encourages the users understanding reflection into the design view.

\section{Findings}

In this paper, the findings include how the multicultural factor can influence on the accessibility designing and how the UCD approach can improve the designing view. According to the discussion from the source (Evers, 2000; Evers and Day, 1997; Marcus, 2000, 2001), the multicultural factors interpret in terms of some cultural variables like Power distance, Uncertainty avoidance, Individualism, Universalism, Masculinity, Neutral Culture, Specific culture and Achievement level during the designing of web accessibility. According to the previous review, the design differences by cultural variables that can be influenced on web accessibility are as follows:

- Structure of information presented in the website

- View of information presentation and symbols, logos and official signs.

- Setting the target users, how the users are motivated, and goal achievement 
- Examining how users navigate through the website

- Methods of attracting focus to various parts of the web site

- Mental model used in the website.

- User support methods like a help system

- Content view of the information focused in the website

- User choices options, metaphors and amount of data presented in the website.

The effective and efficient web interaction is important when the website is for multicultural users. According to the above analysis, it is important to consider the users understanding and their preferences during the designing of web accessibility features. The user's total involvement during the accessibility development makes usable and culturally more perfect web interface. According to the above discussion (Evers, 2000; Simons, 2000; Vredenburg et al., 2002), we can consider the findings from the UCD approach that ensures to manifest the real users wants needs and preferences by the six principles. The following points can be noted from the findings:

Set business goals: This principle involves determining the business goal and participation of design and users. Business goal and users participation is an important factor at the starting of any project. Educational institute can have business goal set for website designing.

Understanding users: The second principle of UCD says that an understanding of the user is the driving force behind all design. Web accessibility features like the setting target users, motivation technique applied in the website, and goal achievement which can be improved with appropriate focus of users understanding. This principle is suited for identifying of users cultural influence.

Designing the total customer experience: This principle focuses the user usefulness and how the product can be easy to use, easy to learn and easy to set-up. The principle of UCD focuses on users experience on product. User choices options, metaphors and amount of data presentation can be determined from the user experience. The user experience needs to focus in designing of accessibility features.

Evaluating designs: This principle of UCD focuses the feedback from the users. Feedback from the users of website helps to direct the design view.

Assessing competitiveness: This principle concerns about the competitive design requirements. The solutions evaluate with users understanding. Assessing this principle can set up the content view of information of website.

Managing for users: This principle focuses on different methods used in website for different cultural users. Method for navigation through the web, mental model set-up and support method can be evaluated as the user's preferences, needs and wants.

\section{Conclusion}

Easily accessible web sites provide opportunities for organizations. The design of the website should focus on the user's satisfactions. The paper has examined that the UCD can become an appropriate method to improve the accessibility features. It is clear that the UCD ensures the users active roles during the design and development phase. The users from different cultures have different needs, wants, preferences and satisfactions about web information. It is difficult to have accessibility features simple and easy for all multi cultural users in the web interface of educational institute, but the design of accessibility should accommodate the cultural difference to achieve the goals of educational institute. According to the findings of the paper, the practical UCD approach in designing of the educational website can have the following steps: 
1. Users involvement from different cultural group

2. Design the accessibility features with the users understanding and participation with observation.

3. Evaluate, manage by continual user's interaction with website

\section{Future Research and Limitations}

There is a clear need for more precise research in this field. No doubt, there is a black hole in between the multicultural users and web accessibility features. Multicultural approach and accessibility features are complicated task. It is difficult to organise all the culture accommodated in one standard frame of accessibility. To improve the accessibility features, the users understanding elements are the one of the main factor, which has been defined in the paper. Collecting and reviewing the more literature of how the UCD approach supports to define the user understanding elements in the multicultural prospective can extend the research in future.

\section{Acknowledgement}

Many thanks to Dr Sue Nielsen for numerous helpful discussions and feedback on earlier drafts of this paper; and to Xavier for his detailed and challenging comments. Thanks to my father Abul Khair Miah to keep myself in study all the time.

\section{References}

Beekhuyzen, J., von Hellens, L., Morley, M. \& Nielsen, S. (2003). Searching for a methodology for smart Internet technology development. Proceedings of the ISD 2003 Conference in Melbourne 25-27 August 2003.

Evers, V. (2000). Cross-cultural understanding of graphical elements on the DirectED website. In A. Smith (Ed.), Proceedings of Annual Workshop on Cultural Issues on HCI. 5 December 2001, Putteridge Bury, University of Luton. Retrieved October 20,2003 from http://www.swi.psy.uva.nl/usr/evers/publications.html

Evers, V. (2001). Cultural aspects of user interface understanding: An empirical evaluation of an e-learning website by international user groups. Doctoral Thesis, the Open University. Retrieved November 4, 2003 from http://www.swi.psy.uva.nl/usr/evers/publications.html

Evers, V. (2002). Cross cultural applicability of user evaluation methods: A case study amongst Japanese, North-American, English and Dutch users. Proceedings CHI 2002, Minneapolis, April 15-20. Retrieved October 20, 2003 from http://www.swi.psy.uva.nl/usr/evers/publications.html

Evers, V. \& Day, D. (1997). The role of culture in interface acceptance. In S. Howard, J. Hammond \& G. Lindegaard (Eds.), Human Computer Interaction INTERACT'97. Chapman and Hall, London. Retrieved October 24, 2003 from http://www.swi.psy.uva.nl/usr/evers/publications.html

Henry, S, L. (2003). Understanding accessibility. Retrieved October 20, 2003 from http://www.uiaccess.com/books.html

IDP Education Australia. (2003). International students in Australian universities. Retrieved 3, November 2003 from http://www.idp.com/marketingandresearch/research/internationaleducationstatistics/article411.asp

Jokela, T. (2000). Usability capability models - Review and analysis. People and Computers XIV - Usability or Else! Proceedings of HCI 2000, Sunderland, UK, Springer, London. pp. 163-181.

Marcus, A. (2000). Cultural dimension and global web design: What ? So what? Now what? Aaron Marcus and Associates, California and New York. Retrieved October 28, 2003 from http://www.amanda.com/resources/hfweb2000/AMA_CultDim.pdf 
Marcus, A. (2001). Cross-cultural user interface design for work, home, play, and on the way. $10^{\text {th }}$ International Conference on Human - Computer Interaction, Crete, Greece, June 22-27, 2003. Retrieved October 28, 2003 from http://www.hcii2003.gr/program/tutorials/t10.asp

Nua Internet Surveys. (2002). How many online?" Retrieved October 28, 2003 from http://www.nua.ie/surveys/how_many_online/

Sierkowski, B. (2002). Achieving web accessibility. The 30th annual ACM SIGUCCS Conference on User services, Providence, Rhode Island, USA, pp 288-291.

Simons, G., F. (2000). Intercultural aspects of online training using games. A keynote speech presented at the International Simulation And Gaming Association (ISAGA) Conference, Tartu, Estonia Retrieved October 7, 2003 from http://www.diversophy.com/archives/gsi_downloads/proced1.pdf

Vredenburg, K., Isensee, S. \& Righi, C., (2002). User centred design: An integrated approach. Software quality institute series. New Jersey: Prentice Hall.

Zaphiris, P. \& Zacharia, G. (2001). Website content accessibility of 30,000 Cypriot web sites" In Proceedings of the 8th Panhellenic Conference on Informatics, November 8-10. Nicosia, Cyprus. Retrieved October 28, 2003 from http://pzaphiri.agrino.org/Papers/accessibility-panhellenic_final.pdf

\section{Biography}

MD Shah Jahan Miah is a student of Master of Information and Communication Technology in the School of Computing and Information Technology, Griffith University. He has completed Master of Information Technology from Griffith University on August 2002. He has been working in an IT company since 4 years. He has experienced in web designing, computer hardware and IT systems. 